\title{
Nephroureterostomy as a treatment of obstructive uropathy: A single center experience
}

\author{
Muhammad Faisal Khan ${ }^{1}$, Maira Saeed Babar ${ }^{1}$, Georgios Tsampoukas ${ }^{2}$, Soumya Misra ${ }^{1}$ \\ ${ }^{1}$ Urology Department North Devon Hospital, Barnstaple, UK; \\ ${ }^{2}$ Urology Department Princess Alexandra Hospital, Harlow, UK.
}

\begin{abstract}
Summary Objective: To report the outcomes of percutaneous nephroureterostomies

performed in a single center a period of ten years.

Materials and methods: We retrospectively collected and analyzed data for 52 nephroureterostomy procedures that were performed from September 2008 to August 2018. We present patient's demographics, indications for the procedure, type of anesthesia, technical difficulties, length of stay in hospital and complications.

Results: A total of 52 procedures including 13 bilateral nephroureterostomies were performed on 39 patients. Taking into account the need for replacement of nephroureterostomy procedures during the study period, total number of procedures was 168. Out of a total 39 patients, 32 (84\%) of patients had advanced cancer. All procedures were performed as day cases using sedation and had no immediate or early complications. Ten patients or 16\% (27 nephroureterostomies out of total 168 procedures) had minor complications.

Conclusions: To the best of author's knowledge, this is the largest case series reporting the outcome of percutaneous nephroureterostomies. We can therefore conclude that percutaneous nephroureterostomy is a useful palliative procedure to relieve ureteric obstruction, when other measures are not possible, and it has low incidence of complications. However, further studies are warranted to compare different procedures used to relieve ureteric obstruction.
\end{abstract}

KEY WORDS: Nephroureterostomy; Ostructive uropathy; Palliation; Nephrostomy; JJ stent.

Submitted 2 March 2020; Accepted 15 March 2020

\section{INTRODUCTION}

Ureteric obstruction is a well-known urological problem that has an overall incidence of $3.1 \%$ rising to $5.1 \%$ in people over age of 60 years (1). It can result in urinary tract obstruction and subsequently may lead to more serious consequences including, renal failure, sepsis or even death. The obstruction can be reversible or irreversible. The etiology of ureteric obstruction includes ureteric calculi, renal papillary necrosis, strictures, pregnancy, renal tract tumors or pelvic masses. In cases where it is not possible to reverse the etiology, methods such as permanent stents, nephrostomies, ureteric diversion and re-implantation or reconstruction become necessary. Some patients are not fit to undergo extensive surgery. This leaves them with options of either stenting, or external diversion of urine with nephrostomy tubes and urinary bag.
Stents (Double J or JJ) and nephrostomies have their advantages and disadvantages. Stents are internalized tubes and hence avoid problems associated with external tubes and bags like wound infections, urine bypassing and leakage of urine, tubes falling out and physical/psychological impact of bags hanging out. Disadvantages include stent failure rate of $16-58 \%$ (2), stent irritation, pain, infections, hematuria, stent encrustations, stone formation and obstruction and blockage of stents. Failure rate due to obstruction secondary to primary prostate, bladder and cervical cancer is high with success rates in the range of $15-21 \%$ (3). However, success rates are relatively higher at more than $50 \%$ (3) in cases of ureteric obstruction secondary to metastatic cancers. Another challenge with stents is the requirement for frequent changes, which involves anesthesia (general or regional). To some extent, frequent changes can be avoided by inserting metallic stents. Theoretically, metallic stents by virtue of being metallic may help mitigating the need for replacement too frequently, however their complications in terms of stent blockage or stent migration have been reported to be around 18\% (4). Nephrostomies, on the other hand have low initial complication rate of up to $3 \%$ (5), and can potentially avoid the requirement for anesthesia and bladder infection, and other complications encountered with stents. However, these can be difficult for patients to manage in community as these can frequently get blocked, bypass urine and can get easily pulled out or fall off requiring frequent unplanned visits to hospital. New et al. (5) in their systematic review reported that patients spend up to $50 \%$ of their remaining time in hospital, though it is not very clear if it is solely due to nephrostomy complications or contributed largely by primary disease and it's related complications. Also for nephrostomy procedures, an experienced interventional radiologist is required which can be a resource issue. Nephrostomy is favoured for patients considered high risk American Society of Anesthesiologist classification (ASA) III + or where stent change is considered difficult. This is true in cases of significant involvement of the bladder by a prostatic or bladder malignancy. This also includes those cases where attempts to identify ureteral orifices fail due to gross haematuria or difficulty in reaching the bladder due to previous surgery or anatomic anomalies $(6,7)$. Nephroureterostomy is a modification of the nephrostomy technique, where the internal drainage tube extends 
from the renal pelvis, down the ureter, into the bladder, therefore, obviating the need for an external bag to collect the urine in most cases. We describe a single center experience of this unique technique in the management of ureteric obstruction. The primary aim was to analyse and report the outcome including complications related to nephroureterostomy in the management of obstructive uropathy.

\section{Materials AND MEthods}

All patients who had the percutaneous nephroureterostomy at our hospital for either malignant or benign conditions causing obstructive uropathy from September 2008 till August 2018 were included in the study. We retrospectively reviewed the computerized record of patient's admission and discharge, clinic letters, radiology reports, laboratory record and radiologist log of the procedure.

We recorded patient's demographics, their disease characteristics and procedural details including indication, technical details, difficulty, and post procedure parameters including length of stay in hospital, and complications requiring unplanned hospital attendances.

We counted the initial procedure with follow up change of nephroureterostomy tubes, which brings the total number of procedures done during the above period to 168 .

\section{Selection criteria}

In patients who were being managed with stents, percutaneous nephroureterostomy was chosen as the final option if they were deemed high risk for general anaesthesia (ASA III and above) or if they had technically difficult stent changes. Patients were also considered for a nephroureterostomy as a palliative solution for life, where a nephrostomy had been initially inserted for renal failure or sepsis related to ureteric obstruction.

\section{Brief overview of the technique}

In preparation for the procedure, we measured skin to renal pelvis distance from the $\mathrm{CT}$ imaging done prior to the procedure. Patients had $160 \mathrm{mg}$ Gentamicin as prophylaxis. Lidocaine 1\% $10 \mathrm{mls}$ was used for local infiltration and Midazolam 0-5 mg and/or Fentanyl 0-50 mg was used for sedation. Patients were monitored throughout the procedure.

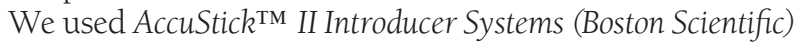
with radiopaque marker for easy detection under image intensifier screening. The procedure is as follows:

1. 21-Gauge diagnostic needle with a stylet is inserted into renal pelvis under ultrasound (USS) guidance. Stylet reduces tissue trauma and bend of needle.

2. Stylet is withdrawn and urine is aspirated from the kidney.

3. This is followed by insertion of a 0.018" kink-resistant nitinol guide wire, which is designed to provide strength.

4. This is followed by a Coaxial sheath/dilator assembly with locking stiffening cannula designed for over-

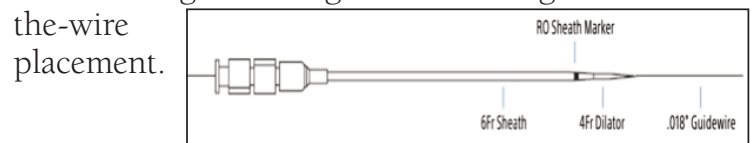

5. Dilator is removed and contrast injected into the renal pelvis to outline anatomy on image intensifier.

6. Once operator is satisfied with the positioning of sheath, nitinol guide wire can be exchanged with a working Bentson $\left(\mathrm{Cook}^{\circledR}\right)$ 0.35" guide wire, which can be advanced down to the bladder and the length of the ureter is measured.

7. If any doubt exists or it is a challenging case due to body mass index (BMI) of patient or any other reason, a second 0.018 " guide wire can be passed alongside the first nitinol wire instead of removing it.

8. The Sheath is removed and "Cook" dilators of 6 French (Fr) and $8 \mathrm{Fr}$ diameter are used to dilate the tract from skin to renal pelvis.

9. This is followed by advancement of Cope nephroureterostomy stent $\left(\mathrm{Cook}^{\circledR}\right)$ " 8.5Fr, tapered end diameter of 0.038 " and ureteric part of stent 22 to $28 \mathrm{~cm}$ long. The length of tube is selected as per measurements made with guide wire length needed to approach bladder from renal pelvis.

10. The external end is locked and closed with a stopper after aspiration of urine from the bladder and kidney and position confirmation with of nephroureterostomy with image intensifier.

\section{The following techniques were used to overcome particular challenges.}

Pelviureteric junction (PUJ) obstruction with dilated renal pelvis:

- The above is procedure is altered at step 7 by aspirating urine from renal pelvis and thus reducing the space and encouraging the guide wire to pass through more easily into ureter.

- If the above step does not work then an TEMPOTM angiographic catheter 4Fr, $65 \mathrm{~cm}$ long and 0.038 " in diameter with tapered and curved end is introduced over the wire to approach the PUJ and help wire slide through the narrow opening.

Tortuous ureter secondary to hydroureter:

- This is again negotiated with the angiographic catheter. The slippery Terumo $^{\circledR}$ angled or straight 0.035 " and $150 \mathrm{~cm}$ long guide wire is advanced to the bend of ureter. Sliding angiographic catheter to the obstruction follows this. The guide wire is then maneuvered around the bend of ureter gradually until it reaches bladder.

Strictures in ureter:

- The slippery Terumo ${ }^{\circledR}$ angled or straight 0.035 " and $150 \mathrm{~cm}$ long guide wire is passed through the stricture. If that is successful then Sterling over the wire balloon dilatation catheterTM (Boston Scientific) is negotiated through the stricture. It is $80 \mathrm{~cm}$ long with a balloon $100 \mathrm{~mm}$ long and $4 \mathrm{Fr}$ (non dilated) to $12 \mathrm{Fr}$ (dilated) in diameter. Once stretched the nephroureterostomy catheter is advanced into the bladder. This dilatation is not the permanent solution of stricture and hence the need for nephroureterostomy remains.

Vesicoureter junction stenosis:

- If the above measures fail and it is a very tight stenosis, the distal end of nephroureterostomy is cut. The distal part of nephroureterostomy then remains in dis- 
tal ureter. It serves the purpose of anchor, providing extra length thus making it difficult for tube to be dislodged. The proximal end of tube is kept open and connected to bag for drainage.

Following the procedure patients are observed in radiology recovery ward for 4 hours and then sent home.

Change of nephroureterostomy is usually a straightforward procedure mostly without or with minimal sedation. The old tube is removed over a guide wire and a new one inserted over the same wire and position checked with image intensifier. However if tube is blocked than mostly insertion of Amplatz super stiff guide wireTM (Boston Scientific) 0.35" in diameter and $145 \mathrm{~cm}$ long, through the tube clears the blockage. If that does not work then the old tube is removed and the procedure is repeated as new.

\section{RESULTS}

A total of 52 nephroureterostomy procedures were done in 39 patients, with 13 patients having bilateral nephroureterostomy. The median age at the time of initial procedure were calculated as 74.7 years (range 39 to 86). The male to female ratio was 3.3:1.

Nephroureterostomy was not used as first line procedure but was reserved after stents or nephrostomy were not longer considered viable options. The aetiologies of the obstructive uropathy were divided into two broad groups: malignant and non-malignant. The vast majority were due to cancer (85\%). In the group with cancer, prostate cancer was the most frequent primary cancer site $(\mathrm{n}=17)$ followed by bladder cancer with 12 patients. Remaining patients had other pelvic malignancies or metastatic disease in the pelvis. These results are summarised in Table 1.

The AP renal pelvic diameter varied from $11 \mathrm{~mm}$ to 56 $\mathrm{mm}$ (median $24.5 \mathrm{~mm}$ ). The calculated skin renal pelvis distance ranged from $3.6 \mathrm{~cm}$ to $20.7 \mathrm{~cm}$ (median $9 \mathrm{~cm}$ ). From the point of view of this study, early complications

\section{Table 1.}

A summary of aetiology of ureteric obstruction.

\begin{tabular}{|lc|}
\hline Reason for obstructive nephropathy & Total number (Percentage) \\
\hline Prostate cancer & $17(43.5 \%)$ \\
\hline Bladder cancer & $12(30.7 \%)$ \\
\hline Benign ureteric stricture & $3(7.6 \%)$ \\
\hline Obstructing stone & $2(5.2 \%)$ \\
\hline Endometrial cancer & $1(2.6 \%)$ \\
\hline Retroperitoneal mass & $1(2.6 \%)$ \\
\hline Colon cancer & $1(2.6 \%)$ \\
\hline Posterior urethral valve & $1(2.6 \%)$ \\
\hline Metastatic breast cancer & $1(2.6 \%)$ \\
\hline
\end{tabular}

\section{Table 2.}

A summary of late complications.

\begin{tabular}{|lcccccc|}
\hline $\begin{array}{l}\text { Total } \\
\text { procedures }\end{array}$ & $\begin{array}{c}\text { Pulled/ } \\
\text { fallen }\end{array}$ & $\begin{array}{c}\text { Leaked/ } \\
\text { bypass }\end{array}$ & Blocked & Infection & $\begin{array}{c}\text { Sepsis } \\
\text { Total } \\
\text { complications }\end{array}$ \\
\hline 168 & $6(3.5 \%)$ & $5(2.9 \%)$ & $6(3.5 \%)$ & 0 & 0 & $17(9.9 \%)$ \\
\hline
\end{tabular}

were defined as ones occurring during or up to 72 hours after the procedure.

There were no early complications. All patients were discharged home the same day from the radiology department without the need for transfer to inpatient wards.

We recorded as late complications when patients attended hospital for advice or treatment in an unplanned way rather than for regular and planned change of nephroureterostomy. The total number of complications was $10(16 \%)$ if measured per nephrostomy initially inserted. This number stands increases to 27 (19\%) if all the follow-up procedures since initial insertion are counted. None of these complications were life threatening or critically significant requiring immediate pharmacological or interventional input. No patients were recorded as having reported pain as the main cause of concern or demanded regular analgesia or removal of nephroureterostomy as a result. There were no infection or sepsis related events. The main complications included pulled/fallen tube, leaked/bypass and blocked tube.

One case was an outlier in respect of number of related hospital attendances. He admitted to self-manipulating tubes as a means to seek medical attention. This led to an exceptionally high number of complications and contributing to $50 \%$ (6 out of total 12) of pulled/fallen tubes, $40 \%$ (3 out of total of 8 ) of leakage/bypass and $14 \%$ (1 out of total of 7) of blocked tube category. Once the social issues were sorted, the patient had no further problems or complications during the last three years of he study period. If we exclude the outlier from the analysis, the complication rate comes down to $9.9 \%$. This is summarized in Table 2.

\section{Discussion}

Our centre is one of the very few centres or perhaps the only centre in the UK performing this radiological-guided procedure for the past few years. It has mainly been performed as a palliative procedure for patients with cancer causing ureteric obstruction. However, it has also been used in our centre for benign conditions.

By conducting a review of the outcome of the procedure, the authors have not only attempted to measure the clinical effectiveness of the procedure for our local centre but also generated baseline data for future reference.

A detailed literature search revealed very few studies that particularly focused on percutaneous nephroureterostomy, and with small numbers, it makes it particularly difficult to compare studies and draw firm conclusions.

We have summarized studies that have captured nephroureterostomy, in Table 3.

This includes case reports $(9,13)$, insertion techniques (10-12), one short outcome analysis of cost and complications among nephroureterostomy and JJ stent (15), case series (16), and one abstract (17). We found one small study in ileal conduits mentioning complication rate of $16 \%$ which is comparable to our study (18).

Monsky et al compared complications for all three types of decompressive procedures but the evaluation was limited to up to 90 days (14) (summarized in Table 4). Apart from the absence of long term follow up data, studies have also differed in the definition of complica- 
Table 3.

A comparative analysis of studies included.

\begin{tabular}{|c|c|c|c|}
\hline Study with year of publica & Type of study & Type of tube & Complications \\
\hline Gemender et al. 2017 (9) & Case report & Neproureterostomy & Tumour seeding from bladder to skin \\
\hline Makramalla et al. 2011 (10) & Techniques of ureteral catheters/tubes & Nephrostomy, nephroureterostomy, Stent & None discussed \\
\hline Taveres et al. 2008 (11) & Technique of insertion in paediatric pyeloplasty & Nephroureterostomy & None discussed. \\
\hline Hadley 2009 (12) & Technique of insertion in paediatric pyeloplasty & $\begin{array}{l}\text { Nephroureterostomy (KISS catheter or kidney } \\
\text { internal splint/stent) }\end{array}$ & $\begin{array}{l}10 \text { patients mean } 13 \text { days. } \\
2 \text { blocked and flushed, } \\
1 \text { pulled + infection and requiring JJ stent } \\
1 \text { Infection. }\end{array}$ \\
\hline Hatzidakis et al. 2014 (13) & Case report for infected obstructed system by hernia & Nephroureterostomy & None \\
\hline Monsky et al. 2013 (14) & $\begin{array}{l}\text { Quality-of-Life assessment after palliative interven- } \\
\text { tions to manage malignant ureteral obstruction }\end{array}$ & $\begin{array}{l}\text { Nephrostomy, Nephroureterostomy and JJ stent for } \\
90 \text { days. }\end{array}$ & * \\
\hline Braģa L.H.P et al. 2008 (15) & $\begin{array}{l}\text { Outcome analysis and cost comparison between } \\
\text { externalized pyeloureteral and standard stents in } \\
470 \text { consecutive open pyeloplasties }\end{array}$ & Nephroureterostomy and JJ stent & $\begin{array}{l}\text { Short-term comparison. } 8.3 \% \text { complications with } \\
\text { Urinoma 1, prolong drainage 5, infection } 1 \text { and } \\
\text { recurrent obstruction } 12 \text { (comparable to JJ stent) }\end{array}$ \\
\hline Spradling et al. 2019 (16) & $\begin{array}{l}\text { Percutaneous nephroureteral tube: a useful tool for } \\
\text { management of intractable hematuria }\end{array}$ & Nephroureterostomy & $\begin{array}{l}\text { Treatment of hematuria with Nephroureterostomy not } \\
\text { responsive to cystoscopy management. (6 patients) }\end{array}$ \\
\hline Mahajan et al. (17) & $\begin{array}{l}\text { Palliative care intervention in oncology: a pictorial } \\
\text { review for the inter- ventional radiologist and the } \\
\text { palliative care physician }\end{array}$ & $\begin{array}{l}\text { Esophageal, duodenal and colonic stenting, } \\
\text { gastrostomy and feeding tubes, percutaneous biliary } \\
\text { drainage and stenting, tunneled peritoneal } \\
\text { catheters, nephrostomy and nephroureterostomy } \\
\text { tubes. } \\
\text { Endobronchial stents, runneled pleural catheters.: } \\
\text { Venous stenting for thoracic outlet obstruction, } \\
\text { vascular access. }\end{array}$ & None mentioned \\
\hline Tal et al. 2003 (18) & $\begin{array}{l}\text { External-internal nephro-uretero-ileal stents in } \\
\text { patients with an ileal conduit: Iong-term results }\end{array}$ & Nephroureterostomy & $\begin{array}{l}1 \text { out of } 16 \text { had recurrent blockages, } 2 \text { out of } 16 \\
\text { recurrent infections, } 3 \text { had failed exchange }\end{array}$ \\
\hline
\end{tabular}

Table 4.

Monsky et al study elaborated further in this table.

\begin{tabular}{|lccc|}
\hline Complications & Nephrostomy (16) & Nephroureterostomy (15) & Stent (15) \\
\hline Dislodged & 7 & 1 & 1 \\
\hline Pain & 4 & 2 & 1 \\
\hline Infection & 3 & 1 & 1 \\
\hline Clogged & 4 & 2 & 0 \\
\hline Leak & 1 & 2 & 0 \\
\hline Fistula & 0 & 0 & 1 \\
\hline Total & 20 & 8 & 4 \\
\hline Quality of life (at 90 days) & Around 3 & Around 3 & Around 3 \\
\hline
\end{tabular}

tions. Our complication rates compare favourably to those reported by Ali and Lee $(19,20)$ and Monsky et al. (14) (Table 5).

Our study has some limitations. This is a retrospective study and the sample size is small. We were unable to measure the quality of life, as this was not recorded at the time. However we can indirectly infer from the data, that all the patients were able to tolerate nephroureterostomy. None of the patients requested removal of nephroureterostomy. All the patients undergoing the procedure did not stay in hospital due to pain or discomfort again suggesting good tolerance to the procedure.

Table 5.

Comparison of different studies complications with our study.

\begin{tabular}{|lcccc|}
\hline Complications & $\begin{array}{c}\text { Ali et al. } \\
\text { Complications of nephrostomy } \\
(\%)\end{array}$ & $\begin{array}{c}\text { Lee et al. } \\
\text { Complications of nephrostomy } \\
(\%)\end{array}$ & $\begin{array}{c}\text { Monsky et al. } \\
\text { Complications of nephroureterostomy } \\
(\%)\end{array}$ & $\begin{array}{c}\text { Our Data } \\
\text { Complications of nephroureterostomy } \\
(\%)\end{array}$ \\
\hline Dislodged & 2.3 & $4.8 \%$ & $6.7 \%$ & $3.5 \%$ \\
\hline Infection/fever & No Data & $13.6 \%$ & $6.7 \%)$ & $0 \%$ \\
\hline Sepsis & $2 \%$ & $3.6 \%$ & $0 \%$ & $0 \%$ \\
\hline Clogged & $5 \%$ & No Data & $13.3 \%$ & $3.5 \%$ \\
\hline Urinoma/extravasation/leak & $0.3 \%$ & $4.3 \%$ & $13.3 \%$ & $2.9 \%$ \\
\hline $\begin{array}{l}\text { Other organs affected } \\
\text { (lieus, pneumonia/atelectasis) }\end{array}$ & No Data & $5.4 \%$ & $0 \%$ & $0 \%$ \\
\hline Bleeding (requiring transfusion) & $2.3 \%$ & $2.4 \%$ & $0 \%$ & $0 \%$ \\
\hline Pain/Intolerance & Not mentioned & Not mentioned & $13.3 \%$ & $0 \%$ \\
\hline Total & $11.9 \%$ & $27.7 \%$ & $53.2 \%$ & $9.9 \%$ \\
\hline
\end{tabular}




\section{Conclusions}

We have reported results of a large case series of percutaneous nephroureterostomy. This procedure appears safe and well tolerated and can be performed as day case using local anaesthetic/sedation.

Further studies are needed to clarify the position of nephroureterostomy amongst other procedures, which provide renal collecting system decompression.

\section{ACKNOWLEDGMENTS}

We acknowledge Dr. Jennifer Macpherson (consultant radiologist) who kindly provided the list of patients who had nephroureterostomy at our hospital.

\section{References}

1. Bell ET. Renal Diseases. $2^{\text {nd }}$ ed. Philadelphia: Lea E Febiger. 1950:122-125.

2. Wong LM, Cleeve LK, Milner AD, Pitman AG. Malignant ureteral obstruction: outcomes after intervention. Have things changed? J Urol. 2007; 178:178-83;

3. Kouba E, Wallen EM, Pruthi RS. Management of ureteral outcomes. J Urol. 2008; 180:444-50.

4. Agarwal S, Brown CT, Bellamy EA, Kulkarni R. The thermoexpandable metallic ureteric stent: an 11-year follow-up. BJU Int. 2009; 103:372-6.

5. New F, Deverill S, Somani BK. Role of percutaneous nephrostomy in end of life prostate cancer patients: a systematic review of the literature. Cent European J Urol. 2018; 71:404-409.

6. Danilovic A, Antonopoulos IM, Mesquita JL, Lucon AM. Likelihood of retrograde double-J stenting according to ureteral obstructing pathology. Int Braz J Urol. 2005; 31:431-6.

7. Uthappa MC, Cowan NC. Retrograde or antegrade double-pigtail stent placement for malignant ureteric obstruction? Clin Radiol. 2005; 60:608-12.

8. North Devon District Hospital leaflet for "Percutaneous Insertion of a Nephroureterostomy tube".

Available from: URL: https://www.northdevonhealth.nhs.uk/wpcontent/uploads/2015/05/percutaneous_insertion_nephroureterostomy_tube.pdf.
9. Gemender M, Rinzler E, Werder G, Trace A. Seeding of a highgrade papillary urothelial carcinoma of the bladder along a nephroureterostomy tract. Radiol Case Rep 2017; 12:542-545.

10. Makramalla A, Zuckerman D. Nephroureteral stents: principles and techniques. Semin Intervent Radiol. 2011; 28:367-379.

11. Taveres A, Manaboriboon N, Lorenzo A, Farhat W. Insertion of an internal-external nephroureteral stent during pediatric laparoscopic pyeloplasty: description of the technique. Urology. 2008; 71:1199-1202

12. Hadley D, Wicher C, Wallis M. Retrograde Percutaneous Access for Kidney Internal Splint Stent Catheter Placement in Pediatric Laparoscopic Pyeloplasty: Avoiding Stent Removal in the Operating Room. J Endourol. 2009; 23:1991-1994.

13. Hatzidakis A, Kozana A, Glaritis D, Mamoulakis C. Right-sided Bochdalek hernia causing septic ureteric obstruction. Percutaneous treatment with placement of a nephroureteral double pigtail. BMJ Case Rep. 2014; 2014:bcr2014207247.

14. Monsky W, Molloy C, Jin B, et al. Quality-of-life assessment after palliative interventions to manage malignant ureteral obstruction. Cardiovasc Intervent Radiol. 2013; 36:1355-1363.

15. Braga L, Lorenzo A, Farhat W, et al. Outcome analysis and cost comparison between externalized pyeloureteral and standard stents in 470 consecutive open pyeloplasties. J Urol. 2008; 180:16931699.

16. Spradling K, Elliott C, Vo H, Reese J. Percutaneous nephroureteral tube: a useful tool for management of intractable hematuria. Urology. 2019; 126:232-235.

17. Mahajan A, Pugash R, Annamalai G, et al. Conference abstract only. International Symposium on Endovascular Therapy (ISET) 2013. JVIR ISET Abstracts 145.e25-145.e26

18. Tal R, Bachar G, Baniel J, Belenky A. External-internal nephrouretero-ileal stents in patients with an ileal conduit: long-term results. Urology. 2004; 63:438-441.

19. Ali SM, Mehmood K, Faiq SM, et al. Frequency of complications in image guided percutaneous nephrostomy. J Pak Med Assoc. 2013; 63:816-20

20. Lee WJ, Patel U, Patel S, Pillari GP. Emergency percutaneous nephrostomy: results and complications. J Vasc Interv Radiol. 1994; 5:135-9.

\section{Correspondence}

Muhammad Faisal Khan, MD

drfaisalkhan@gmail.com

Maira Saeed Babar

Soumya Misra

Urology Department North Devon Hospital, Barnstaple, UK

Georgios Tsampoukas, MD

tsampoukasg@gmail.com

Urology Department Princess Alexandra Hospital, Harlow, UK 